\title{
Editorial
}

\section{Prophylaxis of Post-ERCP Pancreatitis: The Gap between Evidence-Based Guidelines and Clinical Practice}

\author{
Ricardo Rio-Tinto ${ }^{a} \quad$ Jacques Devière ${ }^{a, b}$ \\ a'Digestive Diseases Center, Champalimaud Foundation, Lisbon, Portugal; 'bepartment of Gastroenterology, \\ Hepatopancreatology, and Digestive Oncology, Hôpital Erasme, Université Libre de Bruxelles, Brussels, Belgium
}

\section{Keywords}

NSAIDs · Endoscopic sphincterotomy · Pancreatic stent · Post-ERCP pancreatitis · Prophylaxis · Survey

\section{Profilaxia da pancreatite pós-CPRE: A diferença entre as guidelines baseadas na evidência e a prática clínica}

\section{Palavras Chave \\ AINEs · Esfincterotomia endoscópica · Prótese pancreática · Pancreatite pós-CPRE · Profilaxia . Questionário}

Endoscopic retrograde cholangiopancreatography (ERCP) remains one of the most complex and "risky" endoscopic techniques and the one with a longer learning curve. Pancreatitis is the most common serious complication of ERCP $[1,2]$ and a frequent legal claim for ERCPrelated malpractice. Post-ERCP pancreatitis (PEP) occurs in $2-10 \%$ of unselected patients and in up to $40 \%$ of the high-risk patients [2]. Even for experienced endoscopists, PEP is an unpredictable event, although enough data about risk factors and prophylaxis measures are available. Manipulation of pancreatic ducts is a well-known risk factor for PEP, and pancreatic stent placement is protective for PEP after pancreatic sphincterotomy [3].

The European Society of Gastrointestinal Endoscopy (ESGE) and American Society of Gastrointestinal Endos-

\section{KARGER}

E-Mail karger@karger.com www.karger.com/pjg
(C) 2018 Sociedade Portuguesa de Gastrenterologia Published by S. Karger AG, Basel

Karger

Open access

This article is licensed under the Creative Commons AttributionNonCommercial-NoDerivatives 4.0 International License (CC BYNC-ND) (http://www.karger.com/Services/OpenAccessLicense) Usage and distribution for commercial purposes as well as any distribution of modified material requires written permission. copy (ASGE) published guidelines on PEP prevention in 2014 and 2017, respectively, where both patient- and procedure-associated risk factors are identified, and prophylaxis measures are evidence-based and recommended $[1,4]$. These measures may be as simple and safe as the use of rectal nonsteroidal anti-inflammatory drugs (NSAIDs; indometacin, diclofenac) or more technically demanding as the use of protective pancreatic stents. Systemic interventions, such as periprocedural vigorous hydration, may reduce not only the incidence but also the severity of PEP $[1,4]$.

Comparison between centers may be troublesome as the complexity of treated patients significantly varies. The definition of "personal experience" should not rely only on the number of cases encountered but also take the competence to treat according to complexity into consideration. Well-established grading scales for the degree of the difficulty of ERCP procedures are available $[5,6]$.

In this issue of GE - Portuguese Journal of Gastroenterology, the paper "ERCP in Portugal. A wide survey on the prevention of post-ERCP pancreatitis and papillary cannulation techniques" by Lopes and Canena [7] investigates the compliance of the Portuguese ERCP specialists with the ESGE guidelines for PEP prophylaxis. This survey of the attendants of an ERCP meeting puts the focus on four specific items: (1) technique for biliary cannulation; (2) NSAID use for PEP prophylaxis; (3) attempt to put a protective pancreatic stent after pancreatic guidewire-assisted biliary cannulation; and (4) use of precut as the first rescue technique after cannulation failure. The 
survey comprises a representative sample of 28 Portuguese ERCP specialists and shows surprising results demonstrating an evident discrepancy between evidencebased guidelines and clinical practice. This discrepancy is even more pronounced among the most experienced endoscopists, here defined by the number of procedures per year and procedures not adjusted to their complexity. Not less surprising answers about training in precut, an advanced ERCP technique, show that this was done in an autonomous way by the majority of participants. Unfortunately, the authors did not include any questions about vigorous periprocedural hydration. Although the survey of attendants of an ERCP meeting where the topic to be studied was on debate may have introduced some bias, the results are interesting and should be taken seriously.

The evidence for the use of NSAIDs, a simple and safe measure for PEP prophylaxis, is sufficient for their use in high- and low-risk patients, at least when they have a virgin papilla or when an intervention on the pancreatic duct is intended [1]. This is now adopted as a strong recommendation in all major guidelines. The current study reports the use of NSAIDs by only $54 \%$ of the endoscopists and, even more surprisingly, less use by those who have encountered the largest number of cases. This is again in complete contradiction with the evidence, which shows a beneficial impact even in ERCPs performed by experienced physicians. When compared with a similar survey performed in 2009 [8] when some evidence was already available, but guidelines had not been implemented, the percentage of physicians adequately using NSAIDs has grown from $<20$ to $54 \%$, showing a progressive impact. However, this is still far from being appropriate. The results presented here suggest that a subgroup of physicians does not believe that the use of NSAIDs might have an impact on their own practice; or they do not want to change their habits. Prophylactic pancreatic stenting is indicated in high-risk patients (previous history of PEP, sphincter of Oddi dysfunction, precut, pancreatic sphincterotomy, and multiple PD accesses or injections) $[1,4]$. It is difficult to know the real percentage of physicians doing it, but it is probably $<50 \%$, similar to the results of the survey done 8 years ago [8].

Taken together, the results presented here demonstrate that there is still a lot of work to be done in educating and convincing even the most experienced endoscopists that processing evidence requires large studies on hundreds of patients and cannot just result from "personal experience"; a tendency that we all may have.

The correct identification of high-risk patients and the compliance with the established guidelines are obviously associated with a lower PEP incidence [9]. Therefore, personal experience in ERCP and confidence should not be motives for diverging from evidence-based recommendations. It turns clear that ERCP specialists and trainees must know the importance of PEP prophylaxis measures and follow it. This is true especially for the more experienced ones who assume a low incidence of PEP and therefore consider such prophylaxis measures unnecessary. An advanced course of ERCP is the right setting to not only teach the techniques but also how to prevent complications. This is the reason why such a survey is welcomed and may help standardizing the practice and incrementing the quality of ERCP in Portugal.

\section{Disclosure Statement}

The authors have no conflicts of interest to declare.

\section{References}

1 Dumonceau JM, Andriulli A, Elmunzer BJ, Mariani A, Meister T, Deviere J, et al.; European Society of Gastrointestinal Endoscopy. Prophylaxis of post-ERCP pancreatitis: European Society of Gastrointestinal Endoscopy (ESGE) Guideline - updated June 2014. Endoscopy. 2014 Sep;46(9):799-815.

2 Thaker AM, Mosko JD, Berzin TM. Post-endoscopic retrograde cholangiopancreatography pancreatitis. Gastroenterol Rep (Oxf). $2015 \mathrm{Feb} ; 3(1): 32-40$

3 Hookey LC, RioTinto R, Delhaye M, Baize M, Le Moine $\mathrm{O}$, Devière J. Risk factors for pancreatitis after pancreatic sphincterotomy: a review of 572 cases. Endoscopy. 2006 Jul; 38(7):670-6.
4 Chandrasekhara V, Khashab MA, Muthusamy VR, Acosta RD, Agrawal D, Bruining DH, et al.; ASGE Standards of Practice Committee. Adverse events associated with ERCP. Gastrointest Endosc. 2017 Jan;85(1):32-47.

5 Schutz SM. Grading the degree of difficulty of ERCP procedures. Gastroenterol Hepatol (N Y). 2011 Oct;7(10):674-6.

6 Olsson R, Arnelo U, Swahn F, Lundell B, Enochsson L: The H.O.U.S.E. classification: a novel endoscopic-retrograde-cholangiopancreatography (ERCP) complexity grading scale. BMC Gastroenterol. 2017 Mar;17(1): 38.
7 Lopes L, Canena J: ERCP in Portugal. A wide survey on the prevention of post-ERCP pancreatitis and papillary cannulation techniques. GE Port J Gastroenterol. DOI: $10.1159 / 000487150$.

8 Dumonceau JM, Rigaux J, Kahaleh M, Gomez $\mathrm{CM}$, Vandermeeren A, Devière J. Prophylaxis of post-ERCP pancreatitis: a practice survey. Gastrointest Endosc. 2010 May;71(6):934-9.

9 Riesco JM, Perez-Miranda M, González-Huix F, Alvarez A, Pérez-Roldán F, Gornals J. High Compliance With Guideline Recommendations on Post-ERCP Pancreatitis (PEP) Prevention Is Associated With Low PEP Incidence: Results From a National Spanish Survey. GIE. 2016 May;83(5):AB244. 